\title{
Pacific-wide rejuvenated volcanism related to subduction initiation and Hawaiian-Emperor-Bend formation
}

\author{
K. HOERNLE'*, B. JICHA', J. O'CONNOR', G. \\ YOGODZINSKI', R.D. MÜLLER', F. HAUFF', R. WERNER', \\ M. PORTNYAGIN ${ }^{1}$, R. BEZARD \\ GEOMAR Helmholtz Center, Kiel, Germany \\ 2 University of Wisconsin-Madison, USA \\ ${ }^{3}$ University Erlangen, Nürnberg, Germany \\ + University of South Carolina, Columbia, USA \\ SUniversity of Sydney, Australia \\ - University of Tübingen, Germany
}

Deformation of the seafloor related to subduction initiation and bends in hotspot tracks can cause cracking of the oceanic lithosphere, allowing melts from the upper mantle to erupt on the seafloor. Such volcanism has been reported from the Musician Ridges and Murray Fracture Zone north of the Hawaiian Seamount chain (O'Connor et al., 2015, Nature Geoscience 8). Here we present new age and geochemical data from Mesozoic Pacific seafloor near the northern Emperor Seamounts and the Osbourn Trough outboard the Tonga Arc. As with deformation-related volcanism from the Musicians region, volcanism near the Mesozoic Emperor Seamounts (Smts) and the Osbourn Trough have depleted isotopic compositions (similar to MORB or upper mantle), yielding ages close in time to IzuBonin-Marianas and Tonga arc initiation events ( 53-52Ma) and the Hawaiian-Emperor Bend (HEB; 49-47Ma). A ridge, mapped along the Krusenstern Fracture Zone west of the northern Emperor Smts of Tenji (71Ma) and Suizei (73Ma), yielded an age of 52Ma, as did a sample from the top of a guyot seamount east of these Emperor Smts. A sample from a ridge on the margin of the Emperor Trough east of the Emperor Smts yielded an age of 49Ma. A tuff drilled at DSDP Hole 192A on Meiji Seamount (oldest Emperor Smt, $\sim 85 \mathrm{Ma}$ ) yielded an age of $48 \mathrm{Ma}$. Ages from these volcanic rocks and those from the Osbourn Trough ( 79Ma) fall into the same two age groups (53-52Ma and 49-47Ma) as rejuvenated volcanism from the Musician Ridges. Taken together, these data indicate that the subduction initiation events and formation of the HEB either caused or were associated with Pacific-wide plate deformation, possibly forming by local upwelling and decompression melting of the upper mantle MORB source. These new results also confirm that rejuvenated volcanism on the seafloor can be used to trace and date deformation of oceanic plates related to subduction initiation and plate motion changes. 